\title{
The Clinical Profile of Idiopathic Optic Neuritis at the Ophthalmology OPD of Tertiary Centre of Army Hospital, Nepal
}

\author{
Sagar Rajkarnikar', Anu Gurung ${ }^{1}$, Ram Shrestha' and Shambhu Nath Pant ${ }^{2}$ \\ ${ }^{1}$ Department of Ophthalmology, Nepalese Army Institute of Health Sciences, Shree Birendra Hospital, Chhauni, \\ Kathmandu, Nepal \\ ${ }^{2}$ Department of Community Medicine, Nepalese Army Institute of Health Sciences, Syanobharyang, \\ Kathmandu, Nepal
}

\begin{abstract}
Introduction: Inflammation of the optic nerve is a common cause of visual loss due to optic nerve pathology. This study was conducted to report the clinical features, demographic pattern and response to pulse steroid therapy in patients with idiopathic optic neuritis in a tertiary care teaching institute in Kathmandu, Nepal.

Methods: The hospital data of patients with idiopathic optic neuritis admitted to the Department of Ophthalmology of Shree Birendra Hospital, Chhauni, Kathmandu, Nepal between Jan 2015 to Dec 2018 were retrospectively analysed. The parameters studied were demographic pattern, clinical features, and visual acuity.

Results: Eighteen eyes of 15 patients were found to have optic neuritis (papillits in eight and retrobulbar optic neuritis in 10 eyes). The male to female ratio was 1.4:1. The mean age of the patients was $38.07 \pm 11.37$ years (95\% CI $=31.77-42.37$ ). The most common modes of presentation were loss of visual acuity, painful ocular movement and colour vision defect. One patient had features suggestive of multiple sclerosis. Response to pulse methylprednisolone therapy was good in most (16 eyes) of the cases except for the patients having recurrent episode and started oral steroid elsewhere before presenting to our hospital.

Conclusions: Response to pulse methylprednisolone therapy was good in patients with initial visual acuity of at least perception of light. Demographic and clinical features of our patients were different from those reported from the western world.
\end{abstract}

Key words: demographic pattern; optic neuritis; pulse steroid therapy

Correspondence: Sagar Rajkarnikar, Department of Ophthalmology, Shree Birendra Hospital, Chhauni, Nepalese Army Institute of Health Sciences, Syanobharyang, Kathmandu, Nepal. Email: sagarraj0@gmail.com

DOI: $10.3126 / \mathrm{mj}$ sbh.v20i1.28789

Submitted on: $2020-05-06$

Accepted on: 2021-01-09

This work is licensed under creative common license:

http://creativecommons.org/licenses/by-nc-nd/4.0/ (C) MJSBH 2020 


\section{INTRODUCTION}

Optic neuritis is inflammation of the optic nerve, the structure that connects the eye to the brain. The optic nerve consists of nerve tracts (axons) that originate in the retina of each eye. The optic nerve carries visual information from the retina to the nerve cells in the brain stem, where the information is relayed to the area of the brain that recognises vision (the occipital cortex). Optic neuritis is classically divided into typical (idiopathic) and atypical types, depending on the absence of any other inflammatory disease other than multiple sclerosis (MS) or by evidence of inflammatory disease respectively. ${ }^{1}$

Idiopathic optic neuritis presents with sub-acute loss of central vision with or without pain. This condition is known to improve with or without therapy. Recognition of this condition is important due to its association with multiple sclerosis (MS) particularly in adults. Proper initial therapy with corticosteroids or interferons has shown to halt or delay the onset of multiple sclerosis in these patients. $^{1}$

There are a few studies available on this subject from the eastern part of the world, particularly from India, Nepal, Japan, China, Taiwan and Singapore, which show different demographic characteristics than those described in optic neuritis treatment trial $^{2}$ or in literature from the other part of world. $0^{3-6}$ However, in the context of our country, there is lack of research on this subject. Hence, we intended to study the demographic patterns, presentation as well as response to steroid therapy in our region of the world.

\section{METHODS}

This was a retrospective study conducted in Shree Birendra Hospital, Chhauni, Kathmandu, Nepal. Our institute is the tertiary care central hospital dedicated to Nepalese Army personnel and their dependents. The patients hospitalised with the diagnosis of idiopathic optic neuritis during Jan 2015 to Dec 2018 were included in the study. Their data were obtained from the hospital records and analysed retrospectively. The study was conducted after taking the ethical approval from our institute. Informed consent was obtained from all the patients. Optic neuritis was diagnosed by the presence of acute decrease in visual acuity with defective colour vision and relative afferent pupillary defect. The patients having the above features with swelling of optic nerve on ophthalmoscopy were diagnosed as having papillitis and those not having optic nerve swelling were diagnosed as having retrobulbar optic neuritis. The patients with the diagnosis of ischemic, toxic or hereditary optic neuropathy were excluded from the study.

Demographic features including age, gender, race and ocular complaints were noted. Ocular complaints enquired about were ocular pain, headache and painful extraocular movements. Ocular examination included recording of best corrected visual acuity (using refraction and Snellen's chart), colour vision test (with Ishihara's pseudo isochromatic colour vision chart), ocular movements evaluation (to rule out inter-nuclear ophthalmoplegia), swinging torch light test (to record relative afferent pupillary defect), particularly in cases with unilateral involvement) and fundus evaluation under mydriasis (with both direct and indirect ophthalmoscopy).

The patients with the diagnosis of optic neuritis had undergone neurological examination by an internist. MRI was done to rule out other diseases and confirm optic neuritis in all patients. CBC, blood sugar, renal functional test, electrolytes, monitor of blood pressure, ESR, VDRL test for syphilis were also obtained before therapy. Perimetry was obtained using Goldmann perimeter in eyes with visual acuity of at least $6 / 60$ during the initial presentation and on follow up. The patients were treated with pulse methylprednisolone therapy: intravenous methylprednisolone $1 \mathrm{gm} /$ day for three days diluted in $5 \%$ dextrose solution followed by an 11 days' tapering course of oral prednisolone $^{1}$ in all cases presenting within two weeks of decrease in vision. Among the patients, six were serving soldiers and nine were the dependent ones.

\section{RESULTS}

Between Jan 2015 and Dec 2018, we found 15 patients (18 eyes) with the diagnosis of optic neuritis fulfilling the inclusion criteria. The age range of the patients was 17 to 61 years with 
Table 1. Demographic characteristics

\begin{tabular}{|c|c|c|}
\hline $\begin{array}{l}\text { Demographic } \\
\text { Characterisics }\end{array}$ & Number & $\%$ \\
\hline Total number of patients & 15 & \\
\hline Number of eyes & 18 & \\
\hline \multicolumn{3}{|l|}{ Age distribution (years) } \\
\hline Mean +/- SD & $38.07+/-11.37$ & \\
\hline $95 \% \mathrm{CI}$ & $31.77-44.37$ & \\
\hline Median & 34.00 & \\
\hline $\begin{array}{l}\text { Maximum age } \\
\text { (years) }\end{array}$ & 61 & \\
\hline $\begin{array}{l}\text { Minimum age } \\
\text { (years) }\end{array}$ & 17 & \\
\hline Average age & 38.06 & \\
\hline \multicolumn{3}{|l|}{ Sex } \\
\hline Male & 8 & 53.3 \\
\hline Female & 7 & 46.6 \\
\hline Male : Female & $1.4: 1$ & \\
\hline \multicolumn{3}{|l|}{ Race } \\
\hline Chhetri & 8 & 53.3 \\
\hline Brahmin & 3 & 20.0 \\
\hline Newar & 2 & 13.3 \\
\hline Dalit & 1 & 6.6 \\
\hline Magar & 1 & 6.6 \\
\hline
\end{tabular}

gender ratio of $\mathrm{M}: \mathrm{F}=1.4: 1$. Details of demography are elaborated in Table 1.

Of the 15 patients, three $(20 \%)$ had bilateral involvement. One patient had a history of recurrent attacks (disc pallor was noted in the previously affected eye). Most of the patients presented to the hospital between 7 - 14 days of onset of symptoms. The most common symptom was decrease in vision which was found in all patients. Other common symptoms were headache and painful extraocular movements. (Table 2)

In the affected eyes visual acuity ranged from $6 / 18$ to light perception (PL) (Table 3). Visual acuity of less than 3/60 was recorded in 11 eyes $(61.1 \%)$, of which one $(9.09 \%)$ eye had visual acuity of only light perception. Relative afferent pupillary defect (RAPD) was recorded in all unilateral cases while in cases with bilateral involvement, there was no RAPD but had sluggishly reacting pupil. Color vision defect was present in all affected eyes. On investigating color vision by Ishihara chart $94 \%$ eyes were total colour blind and rest $(6 \%)$ were with red-green deficiency.
Table 2. Clinical features

\begin{tabular}{|c|c|c|}
\hline Clinical Features & & $\%$ \\
\hline \multicolumn{3}{|l|}{$\begin{array}{l}\text { Duration of symptoms } \\
\text { (days) }\end{array}$} \\
\hline Mean +/- SD & $\begin{array}{r}5.07+/- \\
4.008\end{array}$ & \\
\hline $95 \% \mathrm{CI}$ & $2.85-7.29$ & \\
\hline 2 days & 5 & \\
\hline 3 days & 4 & \\
\hline 4 days & 1 & \\
\hline 1 week & 2 & \\
\hline 10 days & 2 & \\
\hline 2 weeks & 1 & \\
\hline \multicolumn{3}{|l|}{ Symptoms } \\
\hline $\begin{array}{l}\text { Decrease in vision/ } \\
\text { color vision }\end{array}$ & $\begin{array}{r}\text { All numbers } \\
\text { of eyes }\end{array}$ & 100 \\
\hline Headache & 12 & 80 \\
\hline $\begin{array}{l}\text { Painful extraocular } \\
\text { movement }\end{array}$ & 7 & 46.6 \\
\hline Previous attack & 1 & 6.6 \\
\hline
\end{tabular}

Neurological examinations in all the patients were within normal limits. None of the patients were positive for VDRL test. MRI was normal without any evidence of mass lesion or sinusitis; however, one patient who had obtained MRI scan from elsewhere showed features suggestive of multiple sclerosis (MS).

All of the patients were asked for follow up visit at one month. One patient who had improved visual acuity to $6 / 6$ at the time of discharge, lost on follow up. Visual outcome was recorded better at one month follow up as compare to initial presentation. Color vision, visual field were also recorded better on follow up visit in all eyes. Visual field could not assessed in $94.4 \%$ eyes at the time of presentation so performed visual field test on follow up period in eyes with visual acuity at least $6 / 60$. The details are elaborated in Table 7.

\section{DISCUSSION}

Evaluation of optic neuritis requires a brilliant clinical detail, appropriate laboratory workup and imaging that provides correct etiological diagnosis. Thereafter treatment gives good outcomes and future trick for natural course. ${ }^{1,19}$ Medical literature on idiopathic optic neuritis from the eastern part of the world is limited. . $^{3,7,8,13,17,18}$ 
Table 3. Visual Acuity on presentation, discharge and 1 month follow up

\begin{tabular}{|l|r|r|r|}
\hline Visual Acuity & Presentation & Discharge \\
Last follow \\
\hline $6 / 6-6 / 18$ & 1 & 13 & 13 \\
\hline $6 / 24-6 / 60$ & 0 & 2 & 3 \\
\hline $5 / 60-3 / 60$ & 6 & 2 & 1 \\
\hline $2 / 60-1 / 60$ & 5 & 1 & 0 \\
\hline$<1 / 60-$ PL & 6 & 0 & 0 \\
\hline NPL & 0 & 0 & 0 \\
\hline Total (eyes) & 18 & 18 & 17 \\
\hline
\end{tabular}

Idiopathic optic neuritis is a diagnosis of exclusion. It is important to recognise this condition and rule out other causes of optic neuritis due to differences in management, response to therapy and prognosis. In many aspects, this report is different from the reports of optic neuritis from other parts of the world. The mean age of our patients $(38.07+/-$ 11.37) was similar to that reported in Wang et al 2001 Study, ${ }^{5}$ and Taiwanese study ${ }^{13}$ though our patients were younger than those reported from oriental countries. ${ }^{3-5}$ Females are reported to be involved more frequently in the ONTT ${ }^{2}$ and other studies $^{8-16}$ as against our study, where we found a slight male preponderance, which is in concurrence with the other reports from the eastern region of the world. ${ }^{3-7,17}$

In our study $46.6 \%$ patients had painful ocular movement which is almost similar to Chinese study done by Zhang et $\mathrm{al}^{4}(42.9 \%)$ and $40 \%$ in the study done in Far western and Mid western region of Nepal by Thapa et al. ${ }^{18}$ In other study from Nepal, Godar et al. found higher (58\%) and from India, Saxena et al. also found had higher $(66 \%)$ cases of painful ocular movement. ${ }^{8,9}$ However, in a study done in Eastern Nepal (Das et al. ${ }^{7}$ 33.3\%), in

Table 5. Visual Acuity on presentation, discharge and 1 month follow up

\begin{tabular}{|l|r|r|}
\hline Result & No of eyes & \multicolumn{2}{|c|}{ Percentage } \\
\hline Improved & 16 & 88.8 \\
\hline Decreased & 0 & 0 \\
\hline $\begin{array}{l}\text { Remained } \\
\text { unchanged }\end{array}$ & 2 & 11.1 \\
\hline
\end{tabular}

Table 4. Ocular Characteristics

\begin{tabular}{|l|r|r|r|r|}
\hline \multicolumn{1}{|l|}{ Type } & \multicolumn{1}{l|}{$\begin{array}{l}\text { Papillitis } \\
\text { Optic } \\
\text { Neuritis }\end{array}$} \\
\hline Right eye & 3 & 3 & 6 & 40 \\
\hline $\begin{array}{l}\text { Left eye } \\
\text { Bilateral } \\
\text { involvement }\end{array}$ & 3 & 3 & 6 & 40 \\
\hline $\begin{array}{l}\text { No. of } \\
\text { patients }\end{array}$ & 1 & 2 & 3 & 20 \\
\hline No. of eyes & 7 & 8 & 15 & 100 \\
\hline & 8 & 10 & 18 & 100 \\
\hline
\end{tabular}

Chandigarh (Jain et $\mathrm{al}^{20} 33.4 \%$ ), in Japan (Suehiro et al $\left.^{10} 17.6 \%\right)$ there were relatively fewer cases presenting with painful ocular movement. Uhthoff's symptoms were not observed in any of our patients. We observed there is significantly high occurrence of disease in Chhteri. Such racial variation was already been showed by various studies including ONTT. ${ }^{2,18}$ In our study $94 \%$ eyes were total colour blind and rest (6\%) were with redgreen deficiency. Shrestha et al ${ }^{17}$ also found total colour blind was commoner whereas non-specific colour vision defect was common in the study done by Godar et al. ${ }^{8}$ The ONTT showed mixed redgreen and blue-yellow colour vision defect. Colour vision defect may shift over time. ${ }^{32}$ Thus, colour vision defect cannot be used for the differential diagnosis of optic neuritis. ${ }^{32}$

Majority (72.2\%) of our patients has shown significant improvement in the colour vision post medical intervention as per the standard guidelines (ONTT study guidelines). ${ }^{2,6}$ The reason probably is due to early presentation to our department and consequently early intervention (Mean \pm SD $5.07 \pm$ 4.008 days). In many studies in the past, the reporting time was much longer. 5,7,9,10,16,18-20 We found that majority of the patients were less than 40

Table 6. Results of treatment in colour vision acuity at discharge from the hospital

\begin{tabular}{|l|r|r|}
\hline Result & No of eyes & Percentage \\
\hline $\begin{array}{l}\text { Improved } \\
(>10 \text { plates of Ishihara) }\end{array}$ & 13 & 72.2 \\
\hline Decreased & 0 & 0 \\
\hline $\begin{array}{l}\text { Not improved } \\
(<10 \text { plates of Ishihara) }\end{array}$ & 5 & 27.7 \\
\hline
\end{tabular}


Table 7. Results of treatment in vision filed changes on last follow up

\begin{tabular}{|l|r|r|}
\hline Vision filed changes & No of eyes & \multicolumn{2}{l|}{ Percentage } \\
\hline Centrocecal scotoma & 7 & 43.75 \\
\hline Central scotoma & 5 & 31.25 \\
\hline Enlarged blind spot & 3 & 18.75 \\
\hline Arcuate scotoma & 1 & 6.25 \\
\hline Total & 16 & 100 \\
\hline
\end{tabular}

year $(11,73.3 \%)$. This might be another reason for showing the propounding effect in terms of regaining the colour vision potential. This fact has been shown in other similar studies as well. ${ }^{3-5,7,13}$ While strongly claiming about the improvement, there is a limitation of small sample size and short follow up period which has been discussed in later parts. Visual acuity in most of our patients was poor at the time of presentation, with $94.4 \%$ of eyes having visual acuity $<6 / 60$ at the presentation. None of our patients had no light perception. There was high prevalence $(20 \%)$ patients presenting with no perception of light in the study of Thapa et al ${ }^{18}$ and Das et $\mathrm{al}^{17}(23 \%)$ whereas in the study by Godar et $a 1,{ }^{8}$ there was only $4.5 \%$, similar to ONTT study $(3 \%){ }^{2}$

It has been reported that papillitis optic neuritis is more commonly seen in many studies $5,7-9,15,17,18,20$ whereas retrobulbar optic neuritis was more common in our study $(55.5 \%)$. Similarly finding are also seen in different studies, ${ }^{2,6,11}$ but in the study done by Wakakura et al. ${ }^{3}$ showed both papillitis $(50 \%)$ and retrobulbar $(50 \%)$ optic neuritis occurred equally. The occurrence of bilateral optic neuritis in our study (20\%) (Table 4) is almost similar to the study of Wang et al ${ }^{5}(19 \%)$ which is lesser to that of studies done in Nepal by other researchers. ${ }^{7,8,18}$ Unilateral optic neuritis was more than bilateral optic neuritis similar to the study in Nepal ${ }^{8}$, China ${ }^{4}$ and Japan. ${ }^{10}$ In contradictory study from Eastern Nepal, ${ }^{7}$ more cases of bilateral optic neuritis was shown whereas another centre in Kathmandu ${ }^{17}$ showed equal number of unilateral and bilateral cases.

We found more than three-fourths of our patients responded to pulse methylprednisolone therapy, which is in accordance with the ONTT study ${ }^{2}$ report and the studies published from Japan and
Singapore. $^{3-6}$ Our study showed beneficial effect of the pulse steroid therapy in the Nepalese population. On the follow up, we assessed visual field in the patients with visual acuity $>6 / 60$. Among them, $43.75 \%$ had centrocecal scotoma which was the commonest visual field defect. Godar $\mathrm{M}$ et al. also found similar defect in their study. ${ }^{8}$ In contrast to our study, Chandigarh study (Jain et al. ${ }^{20}$ ) reported concentric contraction was the commonest visual field defect in optic neuritis. Similar to our study, central, centrocecal, arcuate scotoma, enlarged blind spot were common field defect in different studies. ${ }^{7,9}$

It is well known that optic neuritis is the first clinical manifestation in approximately $20 \%$ of patients with MS. ${ }^{21}$ In regions of high MS prevalence, the majority of patients with optic neuritis have the condition in association with MS. The prevalence of MS exhibits a large variation with regard to both ethnicity and geographical area. ${ }^{22}$ Prevalence rates can be as high as 200 cases per 100,000 in regions located at high latitude such as Scotland and Ireland. ${ }^{23,24}$ In general, the prevalence is about $0.22-8.6$ per 100,000 across Asia. Within Asia the lowest prevalence is found in India at $0.22-0.6$ per $100,000,25-28$ and the highest prevalence is reported in Mediterranean populations (Jordan and Palestine, 20 - 42 per 100,000). ${ }^{29}$ No underlying etiology could be found in our study similar to other study done in Nepal by Godar et al., ${ }^{8}$ Shrestha et al., ${ }^{17}$ and in China (Zang et $\left.\mathrm{al}^{4}{ }^{4}\right)$. In our study only one case $(6.6 \%)$ was diagnosed as MS. In contradictory study from Japan (Suehira et al. ${ }^{10}$ ) reported $22.8 \%$ cases of optic neuritis associated with MS. We had done MRI in all and no abnormality was noted in the brain or the orbits in any patient. A low conversion rate to MS is perhaps due to the short follow-up period. Having all the patients followed-up is difficult in our part of the world partly because there is a general tendency that most of the patients do not come for follow-up once their symptoms are relieved or if the fellow eye is normal. Longer and proper follow-up is required to find out the incidence of multiple sclerosis in these patients. The patients in our part of the world generally seek ophthalmic consultation only when they are disabled due to poor visual acuity. Since this is a hospital-based study, it may underestimate the 
actual magnitude of the problem. As the economically deprived patients generally present to hospitals when the disease is very disabling, high prevalence of bi-laterality and poor initial vision may have been found in our study.

\section{CONCLUSIONS}

The demographic and clinical characteristics of optic neuritis in eastern Nepal are different from those reported from the western world. However, there is some similarity with those reported from China, Japan and Singapore. Response to pulse methylprednisolone therapy is good in patients with initial visual acuity of at least perception of light.

To cite this article: Rajkarnikar S, Gurung A, Shrestha R, Dhakal S, Thapa K, Pant SN. The Clinical Profile of Idiopathic Optic Neuritis at the Ophthalmology OPD of Tertiary Centre of Army Hospital, Nepal. MJSBH. 2021;20(1):70-6.

\section{REFERENCES}

1. Trobe J D (2001). The neurology of vision. Oxford university press; 2002-236.

2. The Optic Neuritis Study Group Visual function 15 years after optic neuritis: a final follow-up report from the Optic Neuritis Treatment Trial. Ophthalmology. 2008;115:1079-1082. DOI: https://doi.org/10.1016/j.ophtha.2007.08.004

3. Wakakura M, Minei-Higa R, Oono S, Matsui Y, Tabuchi A, Kani K et al. Baseline features of idiopathic optic neuritis as determined by a multicenter treatment trial in Japan. Optic Neuritis Treatment Trial Multicenter Cooperative Research Group (ONMRG). Jpn J Ophthalmol. 1999;43:127-32. DOI: 10.1016/ s0021-5155(98)00072-0.

4. Zhang X, Wang W, Wei W, Wang O, Wei Y, Kermode AG (2008). Etiological profile of presumptive optic neuritis in China. J Clin Neurosci; 15:1346-9.

5. Wang J C, Tow S, Med AT. The presentation, etiology, management and outcome of optic neuritis in an Asian population. Clin and Exp Ophthalmol. 2001;29:312-215. DOI: 10.1046/j.1442-9071.2001.00442.x

6. Beck RW, Trobe JD (1995). What we have learned from the Optic Neuritis Treatment Trial. Ophthalmology; 102:1504-8. DOI: 10.1016/s0161-6420(95)30839-1.

7. Das H, Gautam M, Lavaju P. An overview of idiopathic optic neuritis in eastern Nepal. Nep J Oph. 2010;2(3): 10-15. DOI: https://doi.org/10.3126/nepjoph.v2i1.3698

8. Manita Sunam Godar, Ananda Kumar Sharma, Madhu Thapa, Sanjeeta Sitaula, Shanti Gurung. Demographic pattern and clinical characteristics of optic neuritis in a tertiary eye care centre. Nepal J Ophthalmol. 2017;9(17): 51-5. DOI: 10.3126/nepjoph.v9i1.17533

9. SaxenaR, Phuljhda S, Menon V, Gadaginamath S, Sinha A, Sharma P. Clinical profile and short term outcomes of Optic Neuritis Patients in India. Indian J Ophthalmol. 2014;62:265-7. DOI: 10.4103/0301-4738.121131

10. Suehiro S, Adachi Usami E, Miyauchi O. Clinical profile of patients with optic neuritis at Ophthalmology Department of Chiba University, Japan. Neuro-ophthalmology. 2002;12:153-62. DOI:10.1076/noph.27.1.153.14293, Corpus ID: 73390927

11. Isayama Y, Takahashi T, Shimoyoma T, Yamadori A. Acute optic neuritis and multiple sclerosis. Neurology. 1982; 32:73-6. DOI: https://doi.org/10.1212/WNL.32.1.73

12. Liu YS, Ko LS. Long term follow up of optic neuritis. Taiwan J Ophthalmol. 1981;20:1-9.

13. Katz B. The dyschromatopsia of optic neuritis: A descriptive analysis of data from the optic neuritis treatment trial. MD Trans Am Ophthalmol Soc. 1995;93:685-708.

14. Schneck ME, Haegerstrom-Portnoy G. Colour vision defect type and spatial vision in the optic neuritis treatment trial. Investigative ophthalmology \& visual science. 1997 Oct 1;38(11):2278-89.

15. Beck RW, Cleary PA, Anderson MM, Keltner JL, Shults WT, Kaufman DL, et at. A randomised controlled trial of corticosteroids in the treatment of optic neuritis. The optic neuritis study group. N Eng J Med. 1992;326(9):581-8. 
16. Bee YS, Lin MC, Wang CC, Sheu SJ. Optic neuritis: clinical analysis of 27 cases. Kaohsiung J Med Sci. 2003;19: 105-112. PMID: 12751870

17. Shrestha R, Pokharel S, Malla OK, Shakya KN. Visual Outcome after Intravenous Methylprednisolone for Optic Neuritis. Nepal J Neurosci. 20074:70-4.

18. Thapa BB, Dhakal Y. Optic neuritis in farwestern and midwestern region of Nepal: A hospital based study. JNGMC 2017;15(1);46-9. DOI: 10.3126/jngmc.v15i1.23563

19. Bhatia R, Singhal A. Optic neuritis: A blurry vision. Neurol India. 2016;60:459-60. DOI: $10.4103 / 0028-3886.103177$

20. Jain IS, Munjal VP, Dhir SP, Gangwar DN. Profile of optic neuritis in Chandigarh and surrounding areas. Indian J Ophthalmol 1981;28:195-200. DOI: http://www.ijo.in/text.asp?1980/28/4/195/28256 PMID: 7287112

21. Confavreux C, Vukusic S, Moreau T, Adeleine P. Relapses and progression of disability in multiple sclerosis. N Engl J Med. 2000;343:1430-8. PMID: 11078767, DOI: 10.1056/NEJM200011163432001

22. Kira J. Multiple sclerosis in the Japanese population. Lancet Neurol. 2003;2:117-27. DOI: 10.1016/ s1474-4422(03)00308-9

23. Rothwell PM, Charlton D. High incidence and prevalence of multiple sclerosis in south east Scotland: evidence of a genetic predisposition. J Neurol Neurosurg Psychiatry. 1998;64: 730-5. DOI: 10.1136/jnnp.64.6.730

24. McDonnell GV, Hawkins SA. High incidence and prevalence of multiple sclerosis in south east Scotland: evidence of a genetic predisposition. J Neurol Neurosurg Psychiatry. 1999;66:411. DOI: 10.1136/jnnp.66.3.411

25. Singhal BS. Multiple sclerosis-Indian experience. Ann Acad Med Singapore. 1985;14:32-6. PMID: 4004124

26. Hung TP, Landsborough D, Hsi MS. Multiple sclerosis amongst Chinese in Taiwan. J Neurol Sci. 1976;27:459-84. DOI: $10.1016 / 0022-510 \times(76) 90214-8$

27. Kuroiwa Y. Clinical and epidemiological aspects of multiple sclerosis in Japan. Jpn J Med. 1982;21:135-140. DOI: 10.2169/internalmedicine1962.21.135

28. Yu YL, Woo E, Hawkins BR, Ho HC, Huang CY. Multiple sclerosis amongst Chinese in Hong Kong. Brain. 1989; 112:1445-67. DOI: 10.1093/brain/112.6.1445

29. al-Din AS, el-Khateeb M, Kurdi A, Mubaidin A, Wriekat A, al-Shehab A, Khalil RW. Multiple sclerosis in Arabs in Jordan. J Neurol Sci. 1995;131:144-9. DOI: 10.1016/0022-510x(95)00092-g 